\title{
Evaluation Of Evacuation Routes And Fire Prevention Management On High Rise Buildings (Case Study: Millenium Ict Center, Medan)
}

\author{
Novrial' ${ }^{1}$ Ginting, G.N $\mathbf{N}^{2}$ \\ 1 Jurusan Arsitektur, Fakultas Teknik, Universitas Sumatera Utara \\ 2 Jurusan Arsitektur, Fakultas Teknik, Universitas Sumatera Utara \\ Jl. Perpustakaan St. J07 Building, Medan, 20155, Indonesia \\ *Email: Anovrial@yahoo.com \\ Diterima: 15 Juni 2019 Direvisi: 26 juni 2019 Online: 25 Juli 2019
}

\begin{abstract}
In the form of evacuation routes, safety handling must be prioritized especially in high-rise buildings. When the fire occurs, the most important thing apart from extinguishing the fire is to bring the occupants out of the building as soon as possible to prevent any casualties. It is necessary to take effective, efficient and integrated fire hazard prevention measures in a management system so that its implementation and renewal can follow the needs. This is also regulated in building regulations and is technically regulated in the Indonesian National Standard. Shopping center building is for example. Shopping center should put more attention to the accessibility aspects of evacuation routes for users. The scoping study of Millennium ICT Center includes the existence of facilities and infrastructure for evacuation and fire management of buildings, evacuation time of building residents, using descriptive study methods with quantitative analytical, and simulation methods using Rockwell Arena Simulation Software. The purpose of this study is to evaluate the effectiveness of accessibility to facilities, infrastructure, and building fire management of Millennium ICT Center as well as evacuation route travel time meet the requirements, safety and comfort standards of building users.
\end{abstract}

Keywords: accessibility, evacuation, rockwell arena simulation software.

\section{INTRODUCTION}

Fire is an oxidation event that involves three elements, namely fuel, oxygen, and sources of energy or heat which results in property loss, injury, and even death (National Fire Protection Association, 2010). According to Ministry of Public Works No.26 / PRT / M / 2008 , fire hazards are caused by potential threats and the degree of exposure to fire from the beginning of the fire to the spread of fire that causes smoke and gas. Therefore fire prevention needs to get serious attention where one that is of concern is a multi-story building. Building according to RI Law No. 28 of 2002 is a physical form of results work construction that merges with the place the position, in part or all of them are above or in land and or water, which functions as a place for humans to carry out their activities, whether for shelter or residence, religious activities, business activities, social activities, culture, or special activities. According to Indrawan (2013), that the dangers of high-rise buildings when a fire occurs is where access to save themselves can be said to be small and limited, it is necessary to take effective, efficient and integrated fire hazard prevention measures in a management system so that the implementation and renewal can follow needs. One type of building that needs to be considered in terms of evacuation and fire control is shopping center buildings or malls. In the regulation of the Minister of Public Works No. 20 / PRT / M-2 09, markets/ shops/shopping centers are included in buildings that are at high risk of fire. The mall is also a public building that is frequented by the general public, so special attention is needed in terms of the evacuation of fires to ensure the safety of each visitor when a fire occurs. Millennium ICT Center is a special electronic shopping center building in the city of Medan North Sumatra. The number of floors in this building is five floors so it requires an emergency evacuation line that is good for all users. So by evaluating the evacuation pathway, it is expected to evaluate the feasibility of the evacuation route, and refer the designers to the design of a good 
evacuation line by the standards in the Mall building.

According to KEPMEN PU No. 26/2008, a building is a physical form of the results of a construction work that integrates with its domicile, part or all of which is above and / or inland and / or water, which functions as a place for humans to carry out their activities, either for occupancy or place of residence, religious activities, business activities, social activities, culture, or special activities. Public buildings are buildings that are used for all kinds of work activities, including : (a) General meeting, (b) Offices, (c) Hotel, (d) Shopping Mall / Mall, (e) Recreation / entertainment, (f) Hospital/care, and (g) Museum. Shopping mall is a shopping center with one core and several major department stores as an attraction for small retailers and restaurants with building typologies such as shops facing the main corridor of Mall 1 or pedestrian which are the main elements of a shopping Mall with functions as circulation and as communal space for the interaction between visitors and traders. (Maitland, 1987). According to the Indonesian National Standard (SNI), fire is a phenomenon that occurs when a material reaches a critical temperature and react chemically with oxygen (for example) which produces heat, flame, light, smoke, water vapor, carbon monoxide, carbon dioxide, or other products and effects. Danger caused by potential threats and the degree of exposure to fire from the beginning of the fire to the spread of fire, smoke and gas generated. And the following is a category of fire and the handling of fire hazards. (a) Class A fire extinguishers are a type of fire extinguisher from ordinary combustible materials such as wood, paper, clothing and the like. (b) Class B fire extinguishers are a type of fire extinguishers from flammable liquid materials such as petroleum, gas, fat and the like. (c) Class C Fire Extinguishers are a type of fire extinguisher from electricity (such as electrical leakage, short circuit), including fires on electrical equipment, and (d) Class D Fire Extinguisher class D is a type of fire extinguishers from metals such as Zeng, Magnesium, Aluminum powder, Sodium, Titanium, and others. Evacuation routes or Exit Rescue Facility is a continuous and unobstructed route or route that must be passed by residents in the event of a fire or other emergency every point/place in the building to a safe place or public road. Evacuation line components include : (a) Exit, corridor and horizontal exit, (b)Class A ramps and class B ramps (to descend), (c) Class B sloping road (for riding), (d) Emergency Stairs. Facilities for completing the safety path that needs to be considered are as follows: (a) Emergency door, (b) Emergency stairs, (c) corridor and direction of the exit, (d) danger warning system, (e) Exit release, and (d) tagging the way out..

\section{METHOD}

Data analysis will be carried out in this study in the form of quantitative data analysis and for the measure of achievement is to use a subjective scale that will obtain the results of objective decisions with analysis using: (a) Indonesian National Standards ( SNI ), and (b) Likert scale. Comparing with Indonesian National Standards ( SNI ), The method used is secondary data in the form of standards obtained from the Indonesian National Standard ( SNI ) is used as a cross-check of primary data in the form of direct observation. With the presentation technique using a comparison table. Comparison Table are used to compare standards with actual conditions in the field. Where each point of the comparison results will have a value that will determine whether the evacuation route facilities and infrastructure in the actual situation in the field have met the standard or not. The comparison table model below follows the comparison table model in the previous research that has been modified in the form of adding the category information column by the author. Likert scale, Rating categories are divided into 3, namely: (a) Meet (M) (b) exist but does not meet (ANTM), (c) Not Meet (TM), then each category is given a value to get the score value, which is fulfilling its value 2 , there is but it does not fulfill its value 1 and does not fulfill its value 0 . After determining the value of each category then look for the $\mathrm{X}$ and $\mathrm{Y}$ values with the formula: $\mathrm{Y}=$ Highest value $\mathrm{x}$ number of points on the standard, $\mathrm{X}=$ The lowest value $\mathrm{X}$ number of points on the standard. After getting the $\mathrm{X}$ and $\mathrm{Y}$ values, then the calculation is done to find the percentage index with the formula:. 
$\%=($ Total Value $/ \mathrm{Y}) 100$

And to determine the interval:

I $=100:$ Total score (Likert)

Then $=100: 3=33$

Result $(\mathrm{I})=33$

(this is the interval from the lowest $0 \%$ to the highest 100\%) Following are the interpretation

criteria based on the interval:

Figures $0 \%-33 \%=$ Meets $(\mathrm{TM})$

Figures $34 \%-67 \%=$ There Are But Not Meets (ANTM)

Figures $68 \%-100=$ Meet $(\mathrm{M})$

Rockwell Arena Software is a process of designing a real system model in the field with the aim of understanding system behavior and evaluating it to improve the performance of a system. This software is equipped with an input analyzer that is useful to find out the distribution of a group of data. Creating Visitor Evacuation Route Based on observations and field conditions, the evacuation route will be determined by hotel visitors. Calculating Individual Evacuation Speeds Calculation of the speed of the individual borders is based on the formula in NFPA 1995 (Method To Calculate The Travel Time). Occupancy density, To find out the standard speed, the density of the occupants of the floor is needed, namely the number of occupants divided by the available evacuation route area. Where:

$$
\begin{array}{ll}
\mathrm{D} & =\text { Density } \\
\mathrm{P} & =\text { Number of occupants } \\
\mathrm{m} 2 & =\text { The area of the average corridor }
\end{array}
$$

Individual speed, From the density of the occupants we can find out the speed of the individual occupants (Table 1).

\begin{tabular}{|c|c|c|c|c|}
\hline $\begin{array}{l}\text { Facility } \\
\text { Type }\end{array}$ & Condition & Density & $\begin{array}{l}\text { Speed } \\
\text { of } \\
\text { People }\end{array}$ & $\begin{array}{l}\text { Specific } \\
\text { Current }\end{array}$ \\
\hline \multirow[t]{2}{*}{$\begin{array}{l}\text { Stairs } \\
\text { (down) }\end{array}$} & Low & $<1.9$ & 1.0 & 0.54 \\
\hline & Optimal & $\begin{array}{ll}1,9 & \text { to } \\
2,7 & \end{array}$ & 0.50 & 0.94 \\
\hline
\end{tabular}

Table 1. The characteristics of each variable regarding the conditions and types of facilities

\begin{tabular}{llllll}
\hline & Medium & $\begin{array}{l}2.7 \\
3.2\end{array}$ & to & 0.28 & 0.77 \\
& & & \\
\hline & Destroyed & $>3.2$ & 0.3 & 0.42 \\
\hline Stairs (up) & Low & $<1.9$ & 0.8 & 0.43 \\
\hline & Opti Mall & 1.9 & to & 0.40 & 0.75 \\
& & 2.7 & & \\
\hline & Medium & 2.7 & to & 0.22 & 0.62 \\
& & 3.2 & & & \\
\hline Corridor & Destroyed & $>3.2$ & 0.10 & 0.32 \\
\hline & Low & $<1.9$ & 1.4 & 0.76 \\
\hline & Opti Mall & 1.9 & to & 0.70 & 1,3 \\
& & 2.7 & & \\
\hline & Medium & 2.7 & to & 0.39 & 1.10 \\
& & 3.2 & & \\
\hline & Destroyed & $>3.2$ & 0.18 & 0.55 \\
\hline
\end{tabular}

Assumption, There are assumptions made so that the understanding of case studies is clearer. (a) All evacuation processes through the main evacuation route. (b) The number of residents on the 6th floor is 78 employees and 1 security person. (c) The number of residents on the 5th floor is assumed to be 200 people because on the 5th floor there is no kiosk but only a cinema and one restaurant, and (d) The number of visitors on the floor 3,2,1 and ground floor (no 4th floor) is assumed to be 500 people because on each floor there are more than 130 kiosks and each kiosk is usually occupied by more than one seller plus visitors and security on duty each floor so that the number 500 is the ideal assumption.

\section{RESULTS AND DISCUSSION}

Analysis of evacuation route facilities, The facilities and infrastructure for evacuation routes according to SNI 03-1745-2000 include (a) fire ladders, (b) Assembly Points, (c) fire doors, (d) signage, and (e) loudspeakers. The other sources used as a comparison are the Minister of Public Works Regulation, which is generally the same as those written in SNI and also according to expert James Patterson, in his book entitled Simplified Design For Building Fire Safety in 1993. Corridor, The corridor at the Millennium ICT Center has met the standards set for the shopping center, which is> 2.6 meters wide. In the corridor there are also no dead spots and corridors are also equipped with clear signs even though signs in some corridors are blocked by retail store pamphlets so that invisible and corridor access in buildings also only serves visitors or traders to walk or carry 
out promotional activities, the corridor is not permitted to be used as a means of distributing goods needed by tenants. Emergency Stairs, There are three emergency stairs in the Millennium ICT Center building where two of them are in the building and do not have protectors such as shafts, doors and, walls that are resistant to fire. So that the two emergency ladders on the north side of the building are not safe used as evacuation routes because when a fire occurs, a fire can reach the emergency ladder area and the ladder does not go directly to the outside area of the building so it can trap people if the fire has spread throughout buildings on the floor below. The last ladder is outside the building and has a protective wall and fire door but the width of the ladder is less than the width of the minimum ladder that has been determined. From the results of the Millennium ICT Center's fire door analysis, it was found that there were two emergency doors at the Millennium ICT Center, namely. Emergency door, north and northeast side of the building. The door is made of iron and red by the standards on SNI. The first door in the north has met the standard but the second emergency door in the northeast is not equipped with fire resistant glass and has a height below the average human height. The door also cannot be opened and is in the corner of the road so it is not known exactly what the function of the door is. Markers, According to SNI signage is intended to facilitate residents to save themselves quickly. The word exit on signage can be adjusted to the local language but it must remain easy to understand and the word exit on signage also has a predetermined size standard. Exit marks must have arrows that point to the evacuation route, and the arrow must be lit. Every sign of the ex must also be illuminated. At the Millennium ICT Center, the writing and size of signage have met the standards and already has a direction. But the signage has not been illuminated by lights. Loudspeaker, There are no special loudspeakers for emergencies placed on emergency stairs. Loudspeakers in buildings Millennium ICT Center only used for building information systems. Gathering Point, The gathering point is right in front of the Millennium ICT Center's main entrance. This gathering point is in the parking area of fourwheeled vehicles, and is less visible because of the high placement of the gathering point and also covered by billboards and billboards. Building Fire Management, The management of fire prevention at the Millennium ICT Center has been compiled in the SOP (Standard Operating Procedure) - PM.OPR-01 where all procedures for fire prevention at the Millennium ICT Center have been written in full and clear (Table 2).

Table 2. Assessment Results of Facilities and Medan ICT Center Millennium Evacuation Line Infrastructure

\begin{tabular}{lcc}
\hline \multicolumn{1}{c}{ Table } & $\begin{array}{c}\text { Rating } \\
\text { Result }\end{array}$ & Information \\
\hline Corridor & $83 \%$ & Exist and Meet \\
\hline $\begin{array}{l}\text { Emergency } \\
\text { Stairs }\end{array}$ & $50 \%$ & Exist But Not Meets \\
\hline Fire door & $64.3 \%$ & Exist But Not Meets \\
\hline Signage & $50 \%$ & Exist But Not Meets \\
\hline Loudspeaker & $50 \%$ & Exist But Not Meets \\
\hline Gathering Point & $37.5 \%$ & Exist But Not Meets \\
\hline $\begin{array}{l}\text { Building Fire } \\
\text { Management }\end{array}$ & $82 \%$ & Exist and Meet \\
\hline
\end{tabular}

Table description:

$\begin{array}{ll}<33 \% & =\text { There and Meet } \\ 34-67 \% & =\text { There But Not Meets } \\ 68 \%-100 \% & =\text { None }\end{array}$

Evacuation Duration, Each person's arrival time Route in the corridor to the emergency stairs is 12.4 seconds with no fastest and longest time. Because on the 6th floor there is only one corridor (Table 3).

(a) Floor 6

Number of visitors : :-

The number of worker : 87

Total : 87 people

$\mathrm{D}_{\text {corridor }} \quad \mathrm{p} /$ (average corridor area $)$

$=87 / 136,125$

$=0.63 \mathrm{p} / \mathrm{m}^{2}$

Referring to table 3.1 for the density $<1.9$, the criteria is low , so it is obtained:

$\mathrm{V}=1.4 \mathrm{~m} / \mathrm{s}$

$\mathrm{T}=$ distance $/$ speed 
Table 3. Evacuation duration in 6th floor

\begin{tabular}{ll}
$\begin{array}{l}\text { Distance } \\
(\mathbf{m})\end{array}$ & Time (s) \\
\hline 17 & 12.4 \\
\hline
\end{tabular}

\section{(b) 5th floor}

The average arrival of each person to the emergency stairs is 27 seconds with the fastest time of 13.9 seconds and the longest time is 51.4 seconds (Table 4). Number of visitors and workers: 200 people (assumption).

$\mathrm{D}_{\text {corridor }}=\mathrm{p} /$ (average corridor area)

$$
\begin{aligned}
& =200 / 354 \\
& =0.6 \mathrm{p} / \mathrm{m}^{2}
\end{aligned}
$$

Referring to table 3.1 for the density $<1.9$, the criteria is low, so it is obtained:

$\mathrm{V}=1.4 \mathrm{~m} / \mathrm{s}$

$\mathrm{T}=$ distance $/$ speed

Table 4. Evacuation duration in the 5th floor

\begin{tabular}{cc}
\hline Distance (m) & \multicolumn{1}{c}{ Time (s) } \\
\hline 31 & 22,1428571 \\
\hline 20 & 14,2857143 \\
\hline 19.5 & 13,9285714 \\
\hline 45.6 & 32,5714286 \\
\hline 72,6 & 51,4285714
\end{tabular}

(c) 3rd floor

The average arrival of each person to the emergency stairs is 27 seconds with the fastest time of 13.9 seconds and the longest time is 51.4 seconds (Table 5). Number of visitors and workers: 500 people (assumption).

$\mathrm{D}_{\text {corridor }}=\mathrm{p} /$ (the average area of the corridor)

$$
=500 / 424.8
$$$$
=1.17 \mathrm{p} / \mathrm{m}^{2}
$$

Referring to table 3.1 for the density $<1.9$, the criteria is low, so it is obtained:

$\mathrm{V}=1.4 \mathrm{~m} / \mathrm{s}$

$\mathrm{T}=$ distance $/$ speed

Table 5. Evacuation duration in 3rd floor

\begin{tabular}{cr}
\hline $\begin{array}{c}\text { Distance } \\
(\mathbf{m})\end{array}$ & \multicolumn{1}{l}{ Time (s) } \\
\hline 31 & 22,1428571 \\
\hline 20 & 14,2857143 \\
\hline 19,5 & 13,9285714 \\
\hline 45,6 & 32,5714286 \\
\hline 72,6 & 51,4285714 \\
\hline
\end{tabular}

(d) 2nd floor

The average arrival of each person to the fire escape is 34.5 seconds with the fastest time of 11.1 seconds and the longest time is 54.6 seconds (Table 6). Number of visitors and workers: 500 people (assumption).

$\mathrm{D}_{\text {corridor }}=\mathrm{p} /$ (the average area of the corridor)

$$
\begin{gathered}
=500 / 424.8 \\
=1.17 \mathrm{p} / \mathrm{m}^{2}
\end{gathered}
$$

Referring to table 3.1 for the density $<1.9$, the criteria is low, so it is obtained:

$\mathrm{V}=1.4 \mathrm{~m} / \mathrm{s}$

$\mathrm{T}=$ distance $/$ speed

Table 6. Evacuation duration in 2nd floor

\begin{tabular}{cc}
\hline $\begin{array}{c}\text { Distance } \\
(\mathbf{m})\end{array}$ & Time (s) \\
\hline 15,6 & 11,1428571 \\
\hline 30 & 21,4285714 \\
\hline 76,5 & 54,64285714 \\
\hline 33 & 23,57142856 \\
\hline 22,25 & 15,8928571 \\
\hline 71,25 & 50,8928571 \\
75,25 & 53,75 \\
63,25 & 45,1785714 \\
47,75 & 34,1071429 \\
\hline
\end{tabular}

(e) 1 st Floor

The average arrival of each person to the emergency stairs is 31.5 seconds with the fastest time of 14.2 seconds and the longest time is 62.7 seconds (Table 7). Number of visitors and workers: 500 people (assumption).

$$
\begin{aligned}
& \mathrm{D} \text { corridor } \quad \mathrm{p} /(\text { average corridor area }) \\
& =500 / 467 \\
& =1.07 \mathrm{p} / \mathrm{m}^{2}
\end{aligned}
$$


Referring to table 3.1 for the density $<1.9$, the criteria is low, so it is obtained:

$\mathrm{V}=1.4 \mathrm{~m} / \mathrm{s}$

$\mathrm{T}=$ distance $/$ speed

Table 7. Evacuation duration in 1st floor

\begin{tabular}{cr}
\hline Distance (m) & \multicolumn{1}{c}{ Time (s) } \\
\hline 20 & 14,2857143 \\
\hline 25 & 17,871429 \\
\hline 33 & 23,5714286 \\
\hline 66,75 & 47,6785714 \\
\hline 87,75 & 62,6785714 \\
31,25 & 22,3214286 \\
45,5 & 32,5 \\
\hline
\end{tabular}

(f) Ground floor

The average arrival of each person to the emergency stairs is 31.25 seconds with the fastest time of 20.7 seconds and the longest time is 52.8 seconds (Table 8). Number of visitors and workers: 500 people (assumption).

$$
\begin{aligned}
\mathrm{D}_{\text {corridor }} & =\mathrm{p} /(\text { average corridor area }) \\
& =500 / 389.3 \\
& =1.2 \mathrm{p} / \mathrm{m}^{2}
\end{aligned}
$$

Referring to table 3.1 for the density $<1.9$, the criteria is low, so it is obtained:

$\mathrm{V}=1.4 \mathrm{~m} / \mathrm{s}$

$\mathrm{T}=$ distance $/$ speed

Table 8. Evacuation duration in ground floor

\begin{tabular}{cr}
\hline Distance (m) & \multicolumn{1}{c}{ Time (s) } \\
\hline 45 & 32,1428571 \\
\hline 40.25 & 28.75 \\
\hline 74 & 52,8571429 \\
\hline 29 & 20,7142857 \\
\hline 30.5 & 21,7857143 \\
\hline
\end{tabular}

Route on emergency stairs from 6th floor to the ground floor (total 5 floors) fastest possibility.

$$
\begin{aligned}
\mathrm{D}_{\text {stairs }} & =2 /(4 \times 1,2 \times 2) \\
& =2 / 9.504=0.2 \mathrm{p} / \mathrm{m}^{2}
\end{aligned}
$$

Referring to table 3.1 for the density $<1.9$, the criteria is low , so it is obtained:

$$
\begin{array}{ll}
\mathrm{V} & =1.0 \mathrm{~m} / \mathrm{s} \\
\mathrm{Q} . & =\text { Distance } / \text { Speed } \\
& =4 / 1=4 \text { seconds }
\end{array}
$$

The longest possibility

$$
\begin{aligned}
\text { D stairs } & =500 /(4 \times 1,2 \times 2) \\
& =500 / 9.504=52.6 \mathrm{p} / \mathrm{m}^{2}
\end{aligned}
$$

Referring to table 3.1 for density> 3.2 enter crush criteria, so that it is obtained:

$$
\begin{array}{ll}
\mathrm{V} & =0.3 \mathrm{~m} / \mathrm{s} \\
\mathrm{Q} . & =\text { Distance } / \text { Speed } \\
& =4 / 0.3=13.3 \text { second }
\end{array}
$$

Analysis of Evacuation Route Modeling Results, From the modeling results obtained, the average total travel time needed by all Millennium ICT Center visitors is 6000 seconds or 100 minutes. This can be seen in the draft simulation results in the "Accumulated Time" column time from the emergency door to the gathering point. As seen in the tables below (Table 9-10).

Table 9. Accumulated Time Result

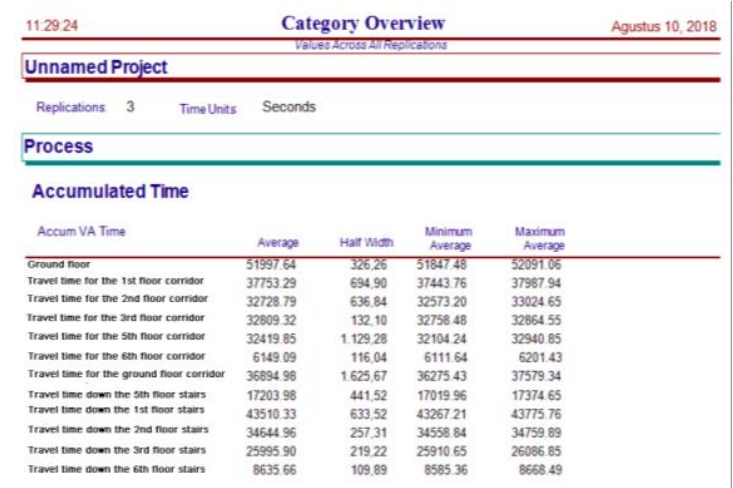

Table 10. Accumulated Time Result Diagram 


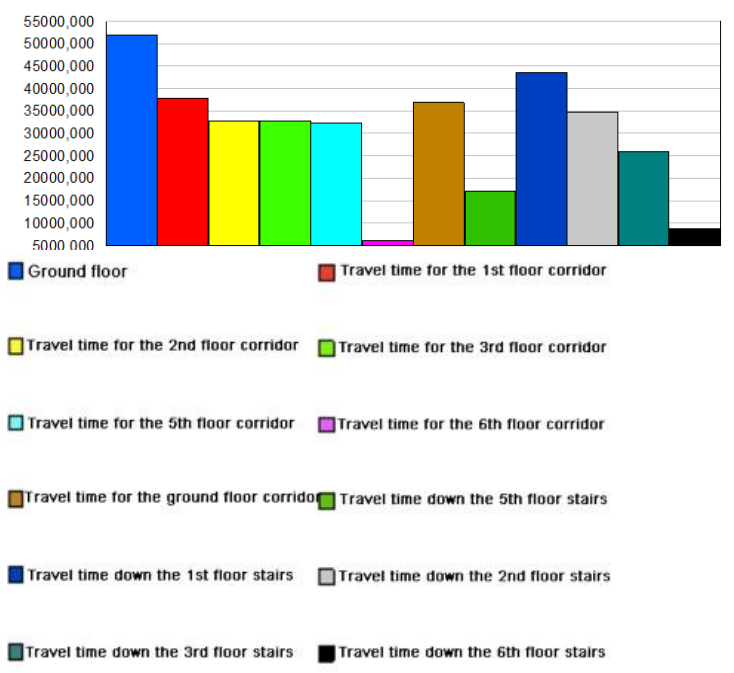

\section{CONCLUSION}

The average value of the evaluation of evacuation routes, facilities, infrastructure and management of Millennium ICT Center fire management is $59.5 \%$ of the total $100 \%$ which can be interpreted as a gathering point in the existing Millennium ICT Center building but does not meet the standards applicable to shopping centers. And based on the results of the data processing using Arena software, the speed of user evacuation in the Millennium ICT Center building is 100 minutes from the maximum time limit for Mall 1 evacuation of 60 minutes which means it has not been able to evacuate building residents effectively.

\section{Acknowledgment}

This research is part of the requirement to obtain a bachelor's degree in the Architecture Department of Universitas Sumatera Utara.

\section{REFERENCES}

Maitland, B. (1987) Shopping Mall Planing and Design. London: London Construction Press.

Rahmayanti, I. (2007. Study Of Fire Protection at Galeria Mall. Final Project of FT UNY.
Stufflebeam, D. (1971) Educational Evaluation and Decision Making. USA: FE Peacock.

Sugiyono (1971) Educational Research Methods Quantitative, Qualitative and $R \& D$ approaches. USA: FE Peacock. 